\title{
Optimal Sizing and Siting of DG in Electrical Networks based on Systematic method
}

\author{
Gopiya Naik, Khatod D.K, Sharma M.P.
}

\begin{abstract}
In this paper a simple and an efficient technique for determining the size(s) and site(s) for Distributed Generation systems in electrical distribution systems is presented for power loss saving and voltage profile improvement, giving suitable weighing factors to each one of the considered objectives. For this purpose a method of analytic has been developed and used, which is based on change in real and reactive parts in the branch currents caused by the DG located, and is tested on a 69-bus electrical network. Obtained results shows best loss reduction as well as voltage profile enhancement of the network under consideration. Among various power factors assumed, the operation of Distributed Generation corresponding to load power factor can enhances the system performance greatly, compared to that at unity power factor.
\end{abstract}

Keywords: Electrical Network, Distributed Generation, Sizing-Siting, Loss Saving, Voltage Drop Reduction.

\section{INTRODUCTION}

Electrical networks are changing rapidly from a large centralized generating systems connected to the large transmission system into a deregulated systems with the provision of connecting small generating plants directly to the distribution networks, very close to the load. These small generating plants are termed as Distributed Generation (DG). Exact size and site of DG in electrical network systems provide benefits such as: technical, economical and environmental to the systems. For this purpose several objectives like power loss reduction [1-16, 20,21, 24, 25], voltage profile improvement $[5,8,11]$ or voltage stability enhancement of the network [3], network investment cost reduction [17- 19], environmental impact reduction [5], etc., has been considered. A variety of analytical methods have been given in the literature. Gozel and Hocaoglu [7] suggested sensitivity based analytic plus equivalent current injection method for siting and sizing of DG in electrical network for real power loss reduction. Wang and Nehrir [16] proposed an analytical phasor current injection approach to place DG considering various types of loading condition on radial and mesh systems to minimize power loss. In [2, 9, 20], analytic approach for optimally allocating the DGs in distribution networks for minimizing the real loss and increased voltage profile was given. A method of loss formula and Genetic Algorithm to real loss minimization in distribution network was given by Shukla et al. [21]. To find

the appropriate site for DG, loss sensitivity analysis was used.
A methodology based on loss sensitivity for allocation of DG in the electrical network to reduce the power loss was proposed by Kashem et al. [22] and Elsaiah et al. [6].

Majority of the methodologies reported in the literature assumes the DG can injects real power only to the system. It is not true, but DGs can feed both real power as well as reactive power into the system, and further improves the performance of the given network in better way. Again, most of the analytic approaches for allocating of DG are based on loss formula [23], which demands more computation. Hence, because of the complexity and special features of the electrical networks the above methods are not appropriate one. A very few analytical techniques for DG sizing and siting have been reported in literature considering combined voltage drop reduction and real loss saving as single objectives. Therefore, a suitable analytical method for DG sizng and siting considering together both real losses and voltage drop needs further attention of research.

\section{PROBLEM FORMULATION}

Modeling of the proposed method is dealt herewith. This method attempts to obtain suitable size and site for DG in a considered electrical systems to reduce real loss and total voltage drop. Following are the assumptions made:

1. The electrical distribution network considered is balanced and radial.

2. Power factor of DG is known in priori.

3. The net real power of DG is equal or less than total real demand power of network under consideration.

Consider a $\mathrm{N}$-bus electrical network as depicted in Fig. 1, wherein $\boldsymbol{I}_{k}$ is the current phasor flowing through branch $k$, while $\boldsymbol{I}_{L k}$ is the load current phasor connected to node $k$.

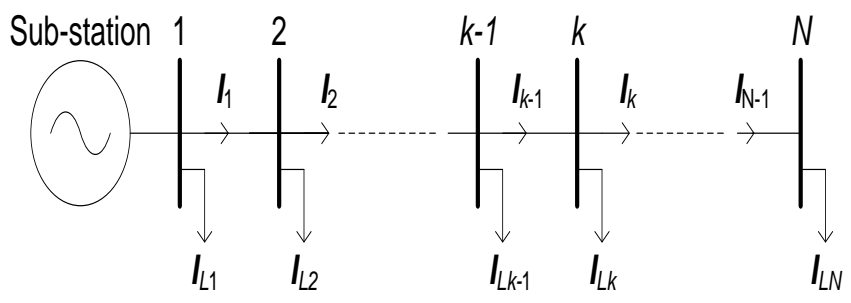

Fig. 1: Typical $N$-bus electrical network
Revised Version Manuscript Received on 10 September, 2019.

Gopiya Naik, Professor, Dept. of EEE, PESCE, Mandya, Karnataka India.(Email: gopiya_s@yahoo.co.in)

Khatod D.K, Professor, Dept. of EEE, IIT Roorkee, Uttarakhand, India.

Sharma M.P., Professor, AHEC, IIT Roorkee, Roorkee-247667, Uttarakhand, India 


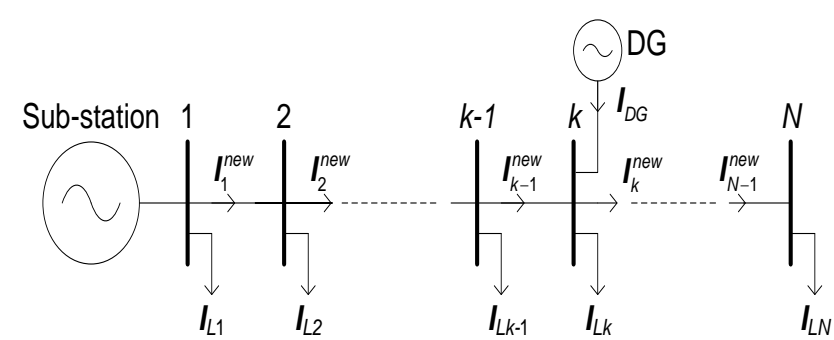

Fig. 2: Typical $N$-bus electrical network with DG connection to bus $k$

Let DG is located at a bus, say, bus $k$ (Fig. 2), injecting current $\boldsymbol{I}_{D G}$ into the network and alters the currents in every branch connected between sub-station bus 1 and bus $k$ without effecting currents in other branches. The current supplied by DG at bus $k$ is given as [25]:

$$
\boldsymbol{I}_{D G}=I_{a D G}+j I_{r D G}=I_{a D G}(1+j \tan \phi)
$$

where, $I_{a D G}$ and $I_{r D G}$ are the real and reactive parts of DG fed current, $\boldsymbol{I}_{D G}$ respectively, and $\phi$ is the phase angle of $\boldsymbol{I}_{D G}$

The modified current in branch $i$ due to DG located at bus $k$ is given as:

$$
\boldsymbol{I}_{i}^{\text {new }}=\boldsymbol{I}_{i}-D_{i} \boldsymbol{I}_{D G}=\left(I_{a i}-D_{i} I_{a D G}\right)+j\left(I_{r i}-D_{i} I_{a D G} \tan \phi\right)
$$

where, $\boldsymbol{I}_{i}$, and $\boldsymbol{I}_{i}^{\text {new }}$ are the phasor current in branch $i$ before DG located and modified current phasor in branch $i$ after DG placement, respectively. The value of $D_{i}$ is given as:

$$
D_{i}= \begin{cases}1, & \text { if branch } i \text { is between bus } 1 \text { and bus } k \\ 0, & \text { otherwise. }\end{cases}
$$

Using the above concept for simultaneous location of $m$ DGs in $N$-bus system, the altered current in branch $i$ is given as:

$$
\boldsymbol{I}_{i}^{n e w}=\boldsymbol{I}_{i}-\sum_{k=1}^{m} D_{i k} \boldsymbol{I}_{D G}^{k}=\left(I_{a i}-\sum_{k=1}^{m} D_{i k} I_{a D G}^{k}\right)+j\left(I_{r i}-\sum_{k=1}^{m} D_{i k} I_{a D G}^{k} \tan \phi^{k}\right)
$$

where, ${ }_{i}^{\text {new }}$ and $\boldsymbol{I}_{D G}^{k}$ are the modified current phasor in branch $i$, current phasor injected by $k^{\text {th }} \mathrm{DG}$, respectively. $I_{a D G}^{k}$ and $\phi^{k}$ are the real part and phase angle of $\boldsymbol{I}_{D G}^{k}$, respectively. The value of $D_{i k}$ is as:

$D_{i k}= \begin{cases}1 ; & \text { if branch } i \text { is between bus } 1 \text { and bus at which } k^{\text {th }} \text { DG is placed } \\ 0 ; & \text { otherwise }\end{cases}$

\subsection{Real Loss Saving}

The total real loss i.e. $P_{L}$ in a $N$-bus electrial network without DG (Fig. 1) is given as [25]:

$$
P_{L}=\sum_{i=1}^{N-1} I_{i}^{2} R_{i}=\sum_{i=1}^{N-1}\left(I_{a i}^{2}+I_{r i}^{2}\right) R_{i}
$$

where, $I_{i}$ is the current in branch $i$ with $I_{a i}$ and $I_{r i}$ the real and reactive parts of it; $R_{i}$ is branch $i$ resistance.
Using eq. (3), the total real loss after $m$ DGs located is given as:

$$
P_{L, \text { new }}=\sum_{i=1}^{N-1}\left(I_{i}^{\text {new }}\right)^{2} R_{i}=\sum_{i=1}^{N-1}\left[\left(I_{a i}-\sum_{k=1}^{m} D_{i k} I_{a D G}^{k}\right)^{2}+\left(I_{r i}-\sum_{k=1}^{m} D_{i k} I_{a D G}^{k} \tan \phi^{k}\right)^{2}\right] R_{i}
$$

From eqs. (4) and (5), the normalized real power loss

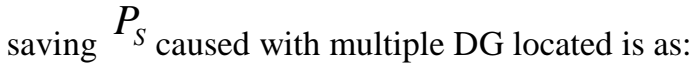

$$
\begin{aligned}
& P_{S}=\frac{P_{L}-P_{L, n e w}}{P_{L}}=\frac{\sum_{i=1}^{N-1}\left(I_{a i}^{2}+I_{r i}^{2}\right) R_{i}-\sum_{i=1}^{N-1}\left[\left(I_{a i}-\sum_{k=1}^{m} D_{i k} I_{a D G}^{k}\right)^{2}+\left(I_{r i}-\sum_{k=1}^{m} D_{i k} I_{a D G}^{k} \tan \phi^{k}\right)^{2}\right] R_{i}}{P_{L}} \\
& =\frac{\sum_{i=1}^{N-1}\left[2 \sum_{k=1}^{m} D_{i k} I_{a D G}^{k}\left(I_{a i}+I_{r i} \tan \phi^{k}\right)-\left(\sum_{k=1}^{m} D_{i k} I_{a D G}^{k}\right)^{2}-\left(\sum_{k=1}^{m} D_{i k} I_{a D G}^{k} \tan \phi^{k}\right)^{2}\right] R_{i}}{P_{L}}
\end{aligned}
$$

\subsection{Voltage Drop Reduction}

The total squared voltage drop, i.e. $V D$ in a $N$-bus electrical network (Fig. 1) is given as:

$$
V D=\sum_{i=1}^{N-1}\left(I_{a i}^{2}+I_{r i}^{2}\right) Z_{i}^{2}
$$

Now, from eq. (3) the total squared voltage drop after $m$ DGs placement is given as:

$$
V D_{\text {new }}=\sum_{i=1}^{N-1}\left(I_{i}^{\text {new }}\right)^{2} Z_{i}^{2}=\sum_{i=1}^{N-1}\left[\left(I_{a i}-\sum_{k=1}^{m} D_{i k} I_{a D G}^{k}\right)^{2}+\left(I_{r i}-\sum_{k=1}^{m} D_{i k} I_{a D G}^{k} \tan \phi^{k}\right)^{2}\right] Z_{i}^{2}
$$

From eqs. (7) and (8), the normalized squared voltage drop reduction, $V D_{S}$ associated with placement of multiple DGs is as:

$$
\begin{aligned}
& V D_{S}=\frac{V D-V D_{n e w}}{V D} \\
& =\frac{\sum_{i=1}^{N-1}\left(I_{a i}^{2}+I_{r i}^{2}\right) Z_{i}^{2}-\sum_{i=1}^{N-1}\left[\left(I_{a i}-\sum_{k=1}^{m} D_{i k} I_{a D G}^{k}\right)^{2}+\left(I_{r i}-\sum_{k=1}^{m} D_{i k} I_{a D G}^{k} \tan \phi^{k}\right)^{2}\right] Z_{i}^{2}}{V D} \\
& =\frac{\sum_{i=1}^{N-1}\left[2 \sum_{k=1}^{m} D_{i k} I_{a D G}^{k}\left(I_{a i}+I_{r i} \tan \phi^{k}\right)-\left(\sum_{k=1}^{m} D_{i k} I_{a D G}^{k}\right)^{2}-\left(\sum_{k=1}^{m} D_{i k} I_{a D G}^{k} \tan \phi^{k}\right)^{2}\right] Z_{i}^{2}}{V D}
\end{aligned}
$$

\subsection{Total Benefit}

From eqs. (6) and (9), the total benefit obtained with multiple DG located is:

$$
f=w_{1} P_{S}+w_{2} V D_{S}
$$

where, $w_{1}$ and $w_{2}$ are the assigned weighting factors to real loss saving and squared voltage drop reduction, respectively and must satisfy the following condition:

$$
w_{1}+w_{2}=1
$$


The DG currents required to cause highest benefit can be got by solving the below equations:

$$
\left.\begin{array}{c}
\frac{\partial f}{\partial I_{a D G}^{1}}=w_{1} \frac{\partial P_{S}}{\partial I_{a D G}^{1}}+w_{2} \frac{\partial V D_{S}}{\partial I_{a D G}^{1}}=0 \\
\frac{\partial f}{\partial I_{a D G}^{2}}=w_{1} \frac{\partial P_{S}}{\partial I_{a D G}^{2}}+w_{2} \frac{\partial V D_{S}}{\partial I_{a D G}^{2}}=0 \\
\vdots \\
\vdots \\
\frac{\partial f}{\partial I_{a D G}^{m}}=w_{1} \frac{\partial P_{S}}{\partial I_{a D G}^{m}}+w_{2} \frac{\partial V D_{S}}{\partial I_{a D G}^{m}}=0
\end{array}\right\}
$$

The partial derivative of $f$ with respect to $p^{\text {th }}$ DG current, $I_{a D G}^{p}$ is given as:

$$
\frac{\partial f}{\partial I_{a D G}^{p}}=2 \sum_{i=1}^{N-1}\left\{D_{i p}\left(I_{a i}+I_{r i} \tan \phi^{p}\right)-D_{i p} \sum_{k=1}^{m} D_{i k} I_{a D G}^{k}\left(1+\tan \phi^{p} \tan \phi^{k}\right)\right\}\left(w_{1} \frac{R_{i}}{P_{L}}+w_{2} \frac{Z_{i}^{2}}{V D}\right)=0
$$

Same as to eq. (12), there will be $m$ linear algebraic equations each identical to eq. (13). These equations in matrix form are:

$$
[\mathbf{A}]_{m \times m}\left[\mathbf{I}_{a D G}\right]_{m \times 1}=[\mathbf{B}]_{m \times 1}
$$

The $(p, q)^{\text {th }}$ elements of matrix $\mathbf{A}$ is computed by:

$$
A_{p q}=\sum_{i=1}^{N-1} D_{i p} D_{i q}\left(1+\tan \phi^{p} \tan \phi^{q}\right)\left(w_{1} \frac{R_{i}}{P_{L}}+w_{2} \frac{Z_{i}^{2}}{V D}\right)
$$

While the $p^{\text {th }}$ element of $\mathbf{I}_{a D G}$ and $\mathbf{B}$ as:

$$
\begin{aligned}
& I_{a D G p}=I_{a D G}^{p} \\
& B_{p}=\sum_{i=1}^{N-1} D_{i p}\left(I_{a i}+I_{r i} \tan \phi^{p}\right)\left(w_{1} \frac{R_{i}}{P_{L}}+w_{2} \frac{Z_{i}^{2}}{V D}\right)
\end{aligned}
$$

From eq. (14), the real parts of injected current by DG is obtained by solving eq. (18):

$$
\left[\mathbf{I}_{a D G}\right]=[\mathbf{A}]^{-1}[\mathbf{B}]
$$

Hence, the size of $k^{\text {th }} \mathrm{DG}$ required is:

$$
\boldsymbol{S}_{D G}^{k}=\boldsymbol{V}^{k} \cdot I_{a D G}^{k}\left(1-j \tan \phi^{k}\right)
$$

where, $\boldsymbol{S}_{D G}^{k}$ is the power apparent of $k^{\text {th }} \mathrm{DG}$ and $\boldsymbol{V}^{k}$ is the voltage phasor of $k^{\text {th }}$ DG. The phase angle of current injected by DG is computed as:

$$
\phi^{k}=\theta^{k}-\cos ^{-1}\left(P F_{D G}^{k}\right)
$$

where, $\theta^{k}$ is the angle of $V^{k}$ and $P F_{D G}^{k}$ is the power factor $k^{\text {th }}$ DG.

\section{SOLUTION ALGORITHM}

The formulated problem in section 2 is utilized to find out the appropriate sizes and sites of DGs in electrical network system. The computational steps involve two broad steps as in $[25]$.

\section{RESULTS AND DISCUSSION}

The proposed algorithm is implemented in MATLAB and is tested on 69-bus electrical distribution networks to determine the suitable size and site for DG systems. For the chosen network, DG power factors are [9]:

a) Unity power factor (UPF) operation of DGs; and

b) DG operating power factor equal to total load power factor (LPF).

\subsection{9-Bus Electrical Network}

The one line diagram of a $12.66 \mathrm{kV}, 69$-bus electrical system is as shown in Fig. 3. The network data are obtained from [26]. The total load is $(3802.19+j 2694.6) \mathrm{kVA}$, with total load power factor of 0.82 lagging. . The base case real and reactive losses in the network are $225 \mathrm{~kW}$ and 102.17 $\mathrm{kVAR}$, respectively.

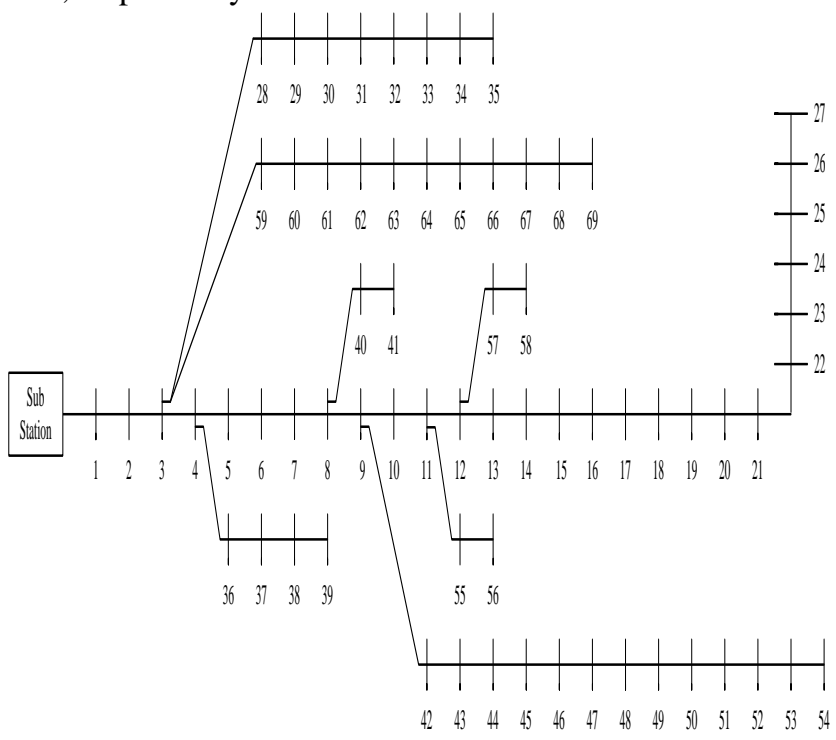

Fig. 3: One line diagram of $12.66 \mathrm{kV}, 69$-bus electrical network

In order to choose the suitable values for $w_{1}$ and $w_{2}$ with UPF DG operation in 69-bus distribution network, the proposed algorithm as given in Section 3 is applied to the test network with different values of $w_{1}$ and $w_{2}$ (value of $w_{1}$ is varied from 0 to 1 in step of 0.1 and using eq. (11), the corresponding value of $w_{2}$ is calculated); and the corresponding benefits (real/active power loss saving and squared voltage drop reduction) are recorded. A plot of real loss saving and squared voltage drop reduction with UPF DG placement for different values of $w_{1}$ is shown in Fig. 4. From this figure, it is seen that with the increase in $w_{1}$, real loss saving is increasing, while voltage drop reduction is decreasing. When $w_{1}=0.0$ and $w_{2}=1.0$, real loss saving is $65.787 \%$ and voltage drop reduction is $65.879 \%$. On the other hand, with $w_{1}=1.0$ and $w_{2}=0.0$, real loss saving is $65.795 \%$ and voltage drop reduction is $65.871 \%$. Both real loss saving and voltage drop reduction are varying in very narrow ranges with the variation in $w_{1}$ and $w_{2}$. In order to give equal weightage to both the objectives, the values of $w_{1}$ and $w_{2}$ are taken as same and equal to 0.5 . 


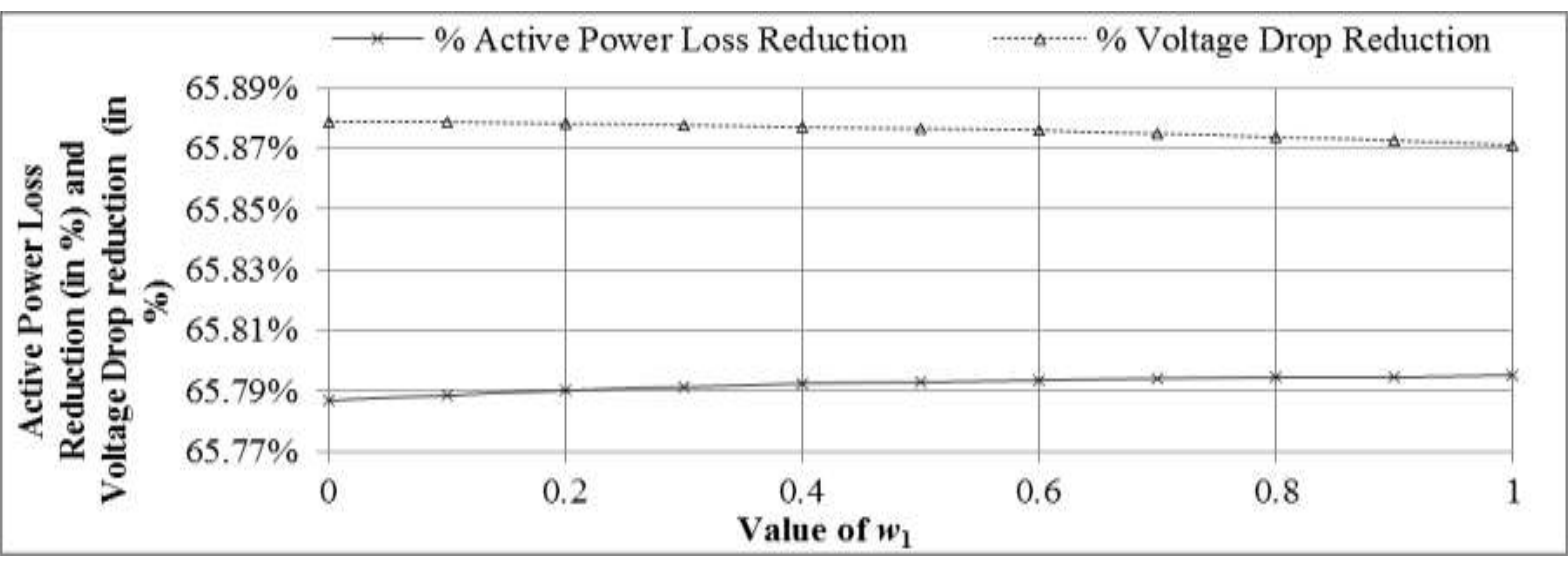

Fig. 4: Real loss saving and voltage drop reduction with UPF DG placement in 69-bus network for different values of $w_{1}$

After choosing $w_{1}=0.5$ and $w_{2}=0.5$, the optimal locations for DG installation at UPF in 69-bus network are determined. For this purpose, first the appropriate size of a single DG for each bus except the sub-station bus and the associated benefits are determined using eqs. (21) and (10), respectively, taking $w_{1}=0.5$ and $w_{2}=0.5$. Fig. 5 shows the appropriate DG size at each bus in the network and corresponding benefits.
Among different buses, placement of a 1.76 MVA, UPF DG at bus 50 offers maximum benefit of $59.11 \%$. Corresponding to this DG size, active loss saving is $59.1 \%$, while squared voltage drop reduction is $59.13 \%$ of their base case values. Hence, a 1.76 MVA, UPF DG is connected at bus 50 and a new load flow solution is obtained.

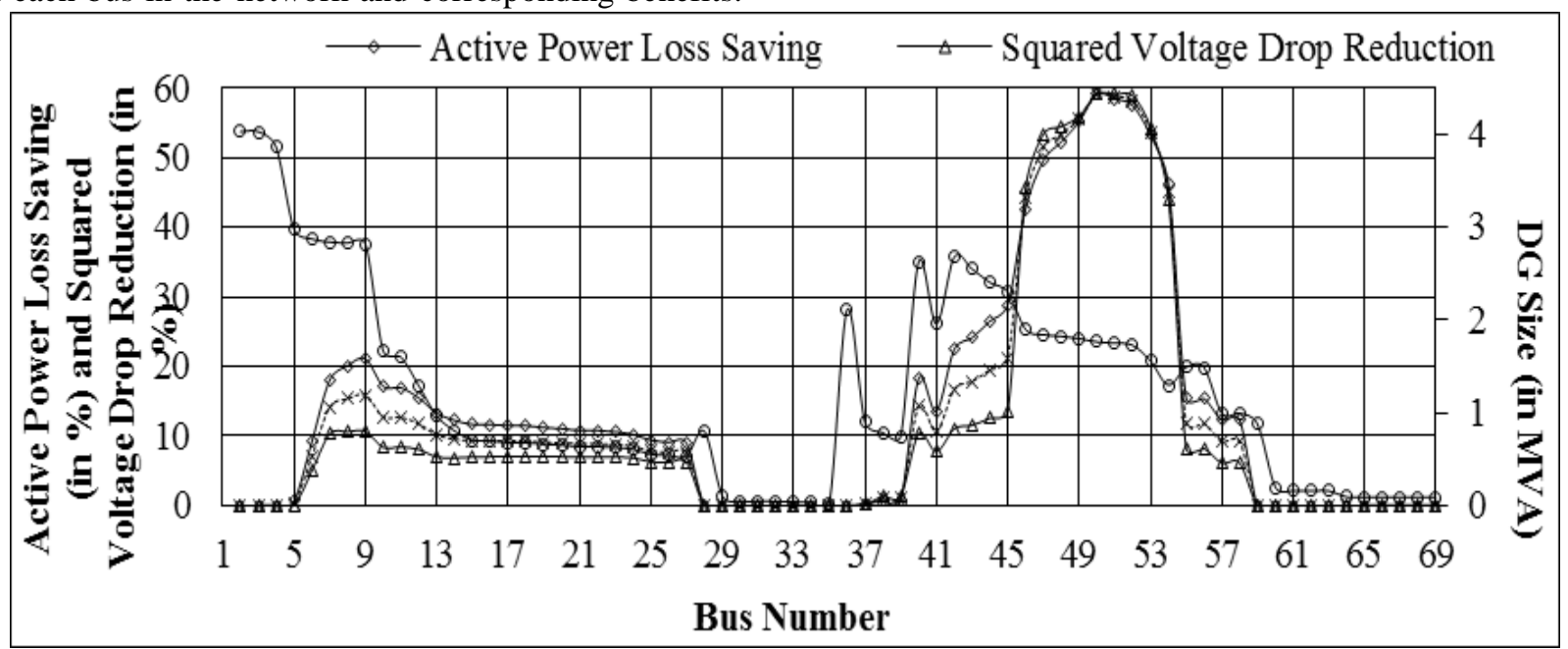

Fig. 5: Maximum real loss saving, voltage drop reduction and optimal size of UPF DG in 69-bus network

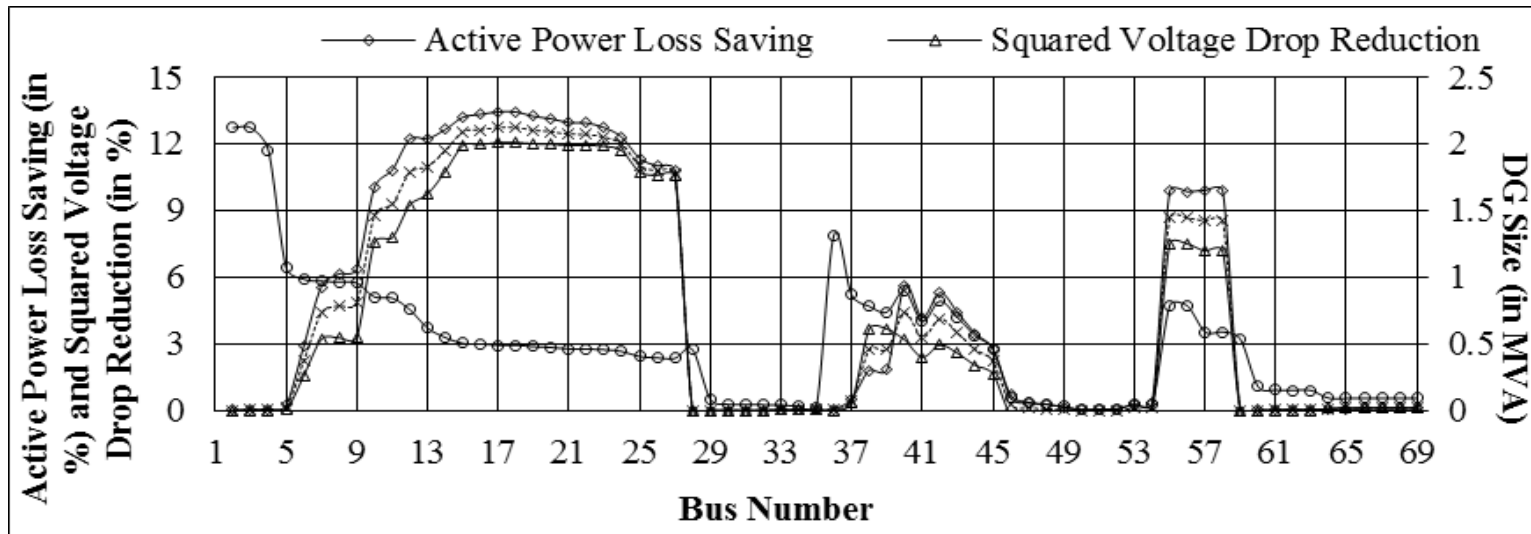

Fig. 6: Maximum real loss saving, voltage drop reduction and optimal size of UPF DG after placing 1.76 MVA, UPF DG at bus 50 in 69-bus network 


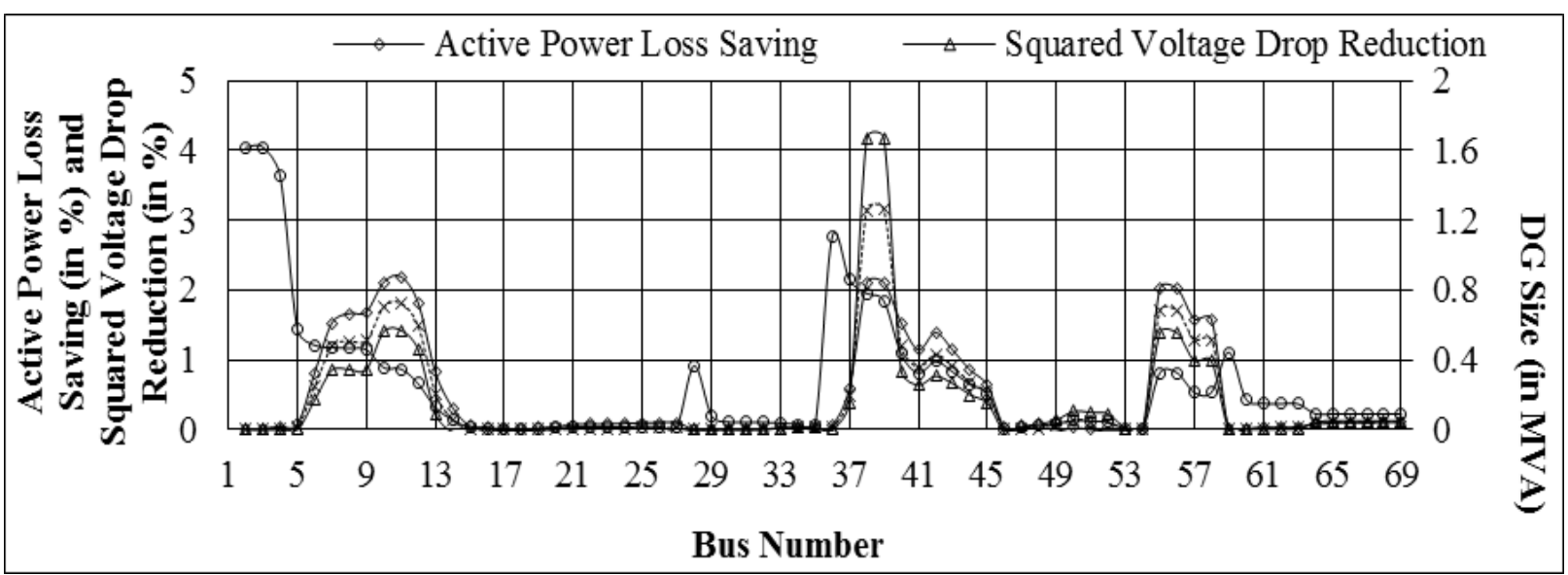

Fig. 7: Maximum real loss saving, voltage drop reduction and optimal size of UPF DG after placing 1.76 and 0.49 MVA, UPF DG at buses 50 and 17, respectively, in 69-bus network

After this, again the appropriate size of a single UPF DG for each bus except the sub-station bus and the corresponding benefits are determined using eqs. (21) and (10), respectively. Fig. 6 shows the optimal DG size for all the buses in the system and associated benefits after placing a 1.76 MVA, UPF DG at bus 50. Among different buses, placement of 0.49 MVA, UPF DG at bus 17 offers maximum benefit of $12.74 \%$. Corresponding to this DG size, real loss saving is $13.44 \%$, while squared voltage drop reduction is $12.06 \%$.Thus, one more UPF DG of 0.49 MVA is placed at bus 17 and a new load flow solution is obtained. At this point, the total real size of DG is $2.25 \mathrm{MW}$.

With 1.76 and 0.49 MVA, UPF DGs at buses 50 and 17, respectively, in the system and taking the same values of $w_{1}$ and $w_{2}$, again the appropriate size of a single DG for each bus and the associated benefits are found using eqs. (21) and (10). Fig. 7 shows the obtained results in terms of appropriate DG size at different buses and corresponding benefits. From this figure, it is observed that among different buses, placement of a 0.74 MVA, UPF DG at bus 39 offers maximum benefit to the network. With this DG size, real loss saving of $2.11 \%$ and squared voltage drop reduction of $4.18 \%$, thus total benefit of $3.15 \%$ can be achieved. Since no significant benefit is observed after placement of third DG in the system, the search procedure for best locations for placement of UPF DGs is stopped and buses 50 and 17 are identified as the best locations for placement of UPF DG.

Table 1: Results for UPF DG placement in 69-bus electrical network with $w_{1}=0.5$ and $w_{2}=0.5$

\begin{tabular}{|c|c|c|c|c|c|c|c|}
\hline \multicolumn{3}{|l|}{ Initial System Condition } & \multicolumn{5}{|c|}{ Result with DG installation } \\
\hline System Description & $\begin{array}{l}\text { Real } \\
\text { Loss } \\
(\mathbf{k W})\end{array}$ & $\begin{array}{l}\text { Squared } \\
\text { Voltage } \\
\text { Drop } \\
\left(\mathbf{k V}^{2}\right)\end{array}$ & $\begin{array}{l}\text { No } \\
\text { DG } \\
\text { placed }\end{array}$ & $\begin{array}{l}\text { Bus for DG } \\
\text { placement }\end{array}$ & $\begin{array}{l}\text { DG Size } \\
\text { (MVA) }\end{array}$ & $\begin{array}{l}\text { Real Loss } \\
\text { Saving } \\
(\mathbf{k W})\end{array}$ & $\begin{array}{ll}\text { Squared Voltage } \\
\text { Drop } & \text { Reduction } \\
\left(\mathbf{k V}^{2}\right) & \end{array}$ \\
\hline Original base case system & 225.00 & 0.179 & 1 & 50 & 1.76 & 132.96 & 0.106 \\
\hline $\begin{array}{l}\text { Base case system with } 1.76 \\
\text { MVA, UPF DG connected to bus } \\
50\end{array}$ & 83.63 & 0.066 & 1 & 17 & 0.49 & 11.24 & 0.008 \\
\hline $\begin{array}{l}\text { Base case system with } 1.76 \text { and } \\
0.49 \text { MVA, UPF DG connected } \\
\text { to buses } 50 \text { and } 17 \text {, respectively }\end{array}$ & 72.16 & 0.058 & 1 & 39 & 0.74 & 1.51 & 0.002 \\
\hline Original base case system & 225.00 & 0.179 & 2 & 17,50 & $0.49,1.71$ & 144.33 & 0.114 \\
\hline $\begin{array}{l}\text { Base case system with } 0.49 \text { and } \\
1.71 \text { MVA, UPF DG connected } \\
\text { to buses } 17 \text { and } 50 \text {, respectively }\end{array}$ & 71.96 & 0.058 & - & - & - & - & - \\
\hline
\end{tabular}

The results for identification of best buses for the placement of UPF DGs in 69-bus network are summarized in Table 1 . The real losses and total squared voltage drop in base case system are $225 \mathrm{~kW}$ and $0.179 \mathrm{kV}^{2}$. Using the proposed technique, an UPF DG of 1.76 MVA size is found suitable for the placement at bus 50 as seen from Fig. 7 and it results in the real loss saving of $132.96 \mathrm{~kW}$ and squared voltage drop reduction of $0.106 \mathrm{kV}^{2}$. After placing $1.76 \mathrm{MVA}$, UPF DG at bus 50, a new load flow solution is obtained which indicates that the system has real loss of $83.63 \mathrm{~kW}$ and squared voltage drop of $0.066 \mathrm{kV}^{2}$. To calculate the site and size of second UPF DG, again the proposed technique is applied to the test system with 1.76 MVA, UPF DG connected at bus 50 and it is found that 0.49 MVA UPF DG at bus 17, as seen from Fig. 17 , offers maximum benefits (real loss saving of $11.24 \mathrm{~kW}$ and squared voltage drop reduction of $0.008 \mathrm{kV}^{2}$ ) to the 
network. After placing 0.49 MVA, UPF DG at bus 17, a new load flow solution is obtained which shows that the network has real loss of $72.16 \mathrm{~kW}$ and squared voltage drop of 0.058 $\mathrm{kV}^{2}$ with 1.76 and $0.49 \mathrm{MVA}$, UPF DG at buses 50 and 17 , respectively.

The proposed technique is further applied to 69-bus network with 1.76 and 0.49 MVA, UPF DG at buses 50 and 17 , respectively, to calculate the site and size of third UPF DG and it is found that $0.74 \mathrm{MVA}$, UPF DG at bus 39 , as seen from Fig. 7, offers maximum benefits (real loss saving of $1.51 \mathrm{~kW}$ and squared voltage drop reduction of $0.002 \mathrm{kV}^{2}$ ) to the network. Since after the placement of third DG in the network, a marginal improvement in the network performance has been seen, no more DG is attempted for siting and sizing and buses 17 and 50 are found best locations for UPF DG installation.

After identifying buses 17 and 50 as the optimal locations for the placement of UPF DG, the optimal sizes of UPF DGs at these buses are determined simultaneously using eqs. (18) to (20). The appropriate sizes of UPF DG at buses 17 and 50 are 0.49 and 1.71 MVA, respectively. By placing these DGs with their calculated size at respective buses, the real loss of $71.96 \mathrm{~kW}$ and total squared voltage drop of $0.058 \mathrm{kV}^{2}$ are observed as shown in Table 1.

The above mentioned approach for placement of UPF DG is extended to size and site the DGs at LPF (0.82 lagging) in 69-bus network. In order to select the suitable values for $w_{1}$ and $w_{2}$ with LPF DG operation in the considered distribution test network, the proposed algorithm is applied to the test network with different values of $w_{1}$ and $w_{2}$; and the corresponding benefits (real power loss saving and squared voltage drop reduction) are calculated for each combination of $w_{1}$ and $w_{2}$. The value of $w_{1}$ is varied from 0 to 1 in step of 0.1 and the corresponding value of $w_{2}$ is calculated from eq. (11). A plot of real loss saving and squared voltage drop reduction with LPF DG placement for different values of $w_{1}$ is shown in Fig. 8. From this figure, it is seen that with increase in $w_{1}$, real loss saving is increasing, while voltage drop reduction is decreasing. When $w_{1}=0.0$ and $w_{2}=1.0$, real loss saving is $98.99 \%$ and voltage drop reduction is $99.18 \%$. On the other hand, with $w_{1}=1.0$ and $w_{2}=0.0$, real loss saving is $99 \%$ and voltage drop reduction is $99.17 \%$. Both real loss saving and voltage drop reduction are varying in very narrow ranges with the variation in $w_{1}$ and $w_{2}$. In order to give equal weightage to both the objectives, the values of $w_{1}$ and $w_{2}$ are taken as same and equal to 0.5 .

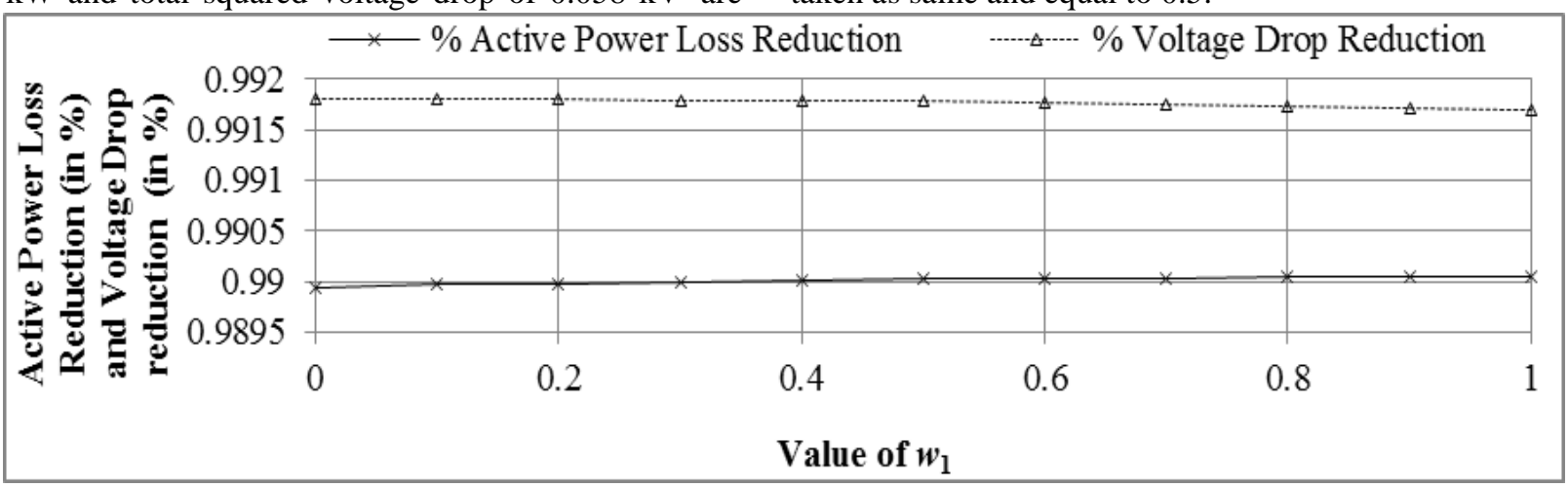

Fig. 8: Real loss saving and voltage drop reduction with LPF DG placement in 69-bus network for different values of $w_{1}$

After selecting $w_{1}=0.5$ and $w_{2}=0.5$, the suitable locations for DG placement at LPF in the given network are determined. For this purpose, first the suitable size of a single DG for each bus except the sub-station bus and the associated benefits are determined from eqs. (21) and (10), taking $w_{1}=0.5$ and $w_{2}=0.5$. Fig. 9 shows the optimal DG sizes at different buses in the network and associated benefits.

Among different buses, placement of a 2.17 MVA, LPF DG at bus 50 offers maximum benefit of $89.3 \%$. Corresponding to this DG size, real loss saving is $89.27 \%$, while squared voltage drop reduction is $89.32 \%$ of their base case values. Hence, a 2.17 MVA, LPF DG is connected at bus 50 and a new load flow solution is obtained.

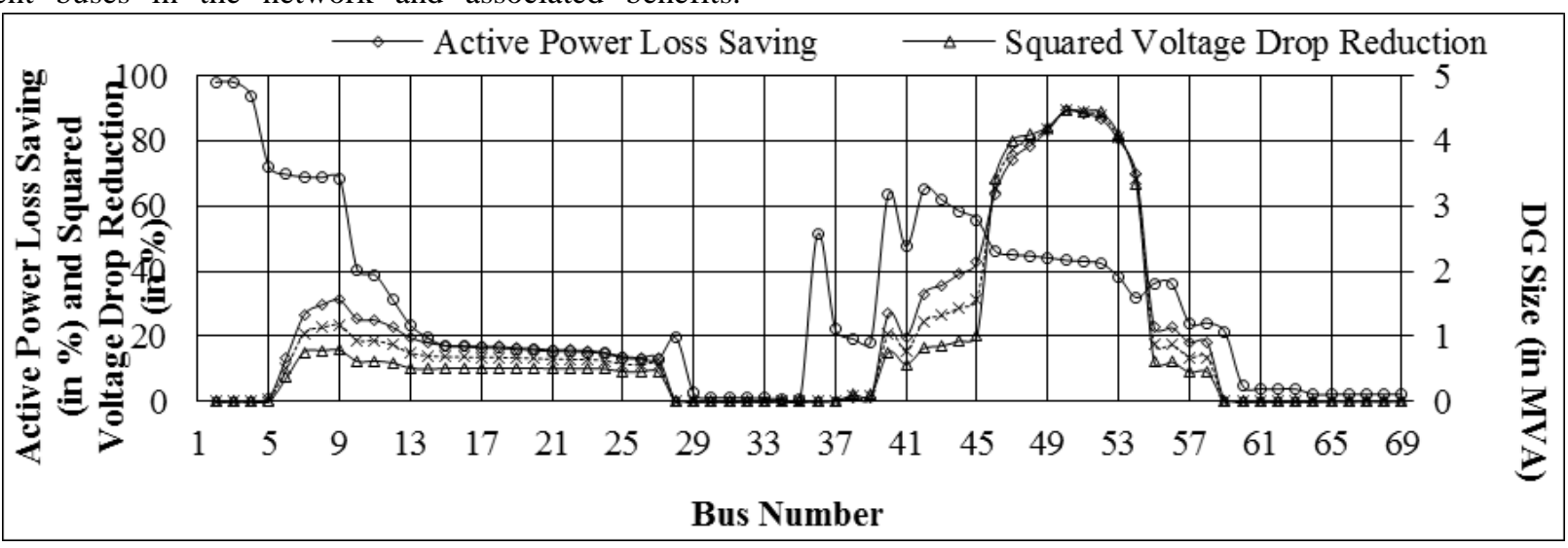

Fig. 9: Maximum real loss saving, voltage drop reduction and optimal size of LPF DG in 69-bus network 


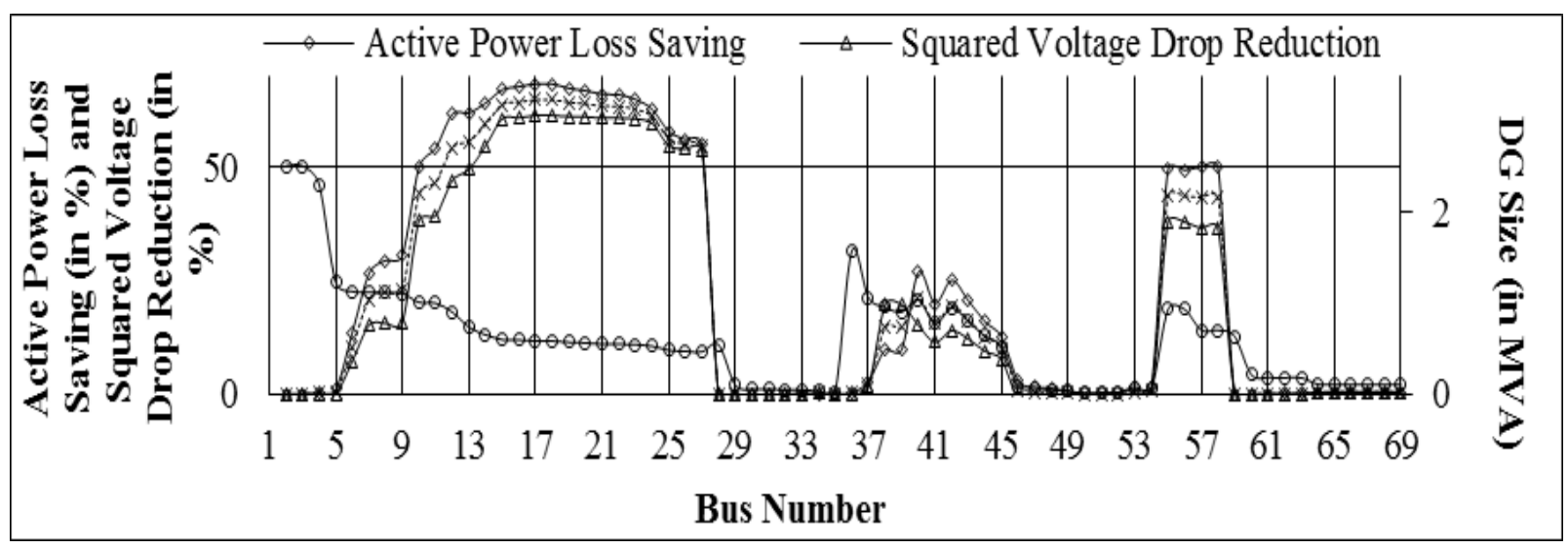

Fig. 10: Maximum real loss saving, voltage drop reduction and optimal size of LPF DG after placing 2.17 MVA, LPF DG at bus 50 in 69-bus network

After placing 2.17 MVA, LPF DG at bus 50 and taking the same values of $w_{1}$ and $w_{2}$, again the suitable size of a single DG for each bus except the sub-station bus and the associated benefits are obtained from eqs. (21) and (10). Fig. 10 shows the optimal DG size at each bus in the system and associated benefits. Among different buses, placement of a 0.59 MVA, LPF DG at bus 17 offers maximum benefit of $64.93 \%$. Corresponding to this DG size, real loss saving is $68.4 \%$, while squared voltage drop reduction is $61.46 \%$. Thus, one more LPF DG of 0.59 MVA is placed at bus 17 and a new load flow solution is obtained. At this point, the total real power capacity of DG is $2.26 \mathrm{MW}$.

With 2.17 and 0.59 MVA, LPF DGs at buses 50 and 17, respectively, in the network and taking the same values of $w_{1}$ and $w_{2}$, again the suitable size of a single DG for each bus and the associated benefits are obtained using eqs. (21) and (10). Fig. 11 shows the obtained results in terms of appropriate DG size at different buses and associated benefits. From this figure, it is observed that among different buses, placement of a $0.91 \mathrm{MVA}$ LPF DG at bus 39 offers maximum benefit to the system. With this DG size, real loss saving of $31.18 \%$ and squared voltage drop reduction of $51.65 \%$, thus total benefit of $41.42 \%$ can be achieved. Hence, 0.91 MVA capacity of LPF DG is connected to bus 39 and a new load flow solution is obtained. At this point, the total MW capacity of DG is $3.01 \mathrm{MW}$.

With 2.17, 0.59 and 0.91 MVA, LPF DGs at buses 50, 17 and 39, respectively, in the system and taking the same values of $w_{1}$ and $w_{2}$, again the appropriate size of a single LPF DG for each bus and the associated benefits are obtained using eqs. (21) and (10). Fig. 12 shows the obtained results in terms of appropriate DG size at different buses and associated benefits. Among different buses, placement of a $0.41 \mathrm{MVA}$, LPF DG at bus 11 offers maximum benefit of $38.15 \%$. Corresponding to this DG size, real loss saving is $42.4 \%$, while squared voltage drop reduction is $33.9 \%$. Thus, one more LPF DG of 0.41 MVA is placed at bus 11 and a new load flow solution is obtained. At this point, the total real power capacity of DG is $3.35 \mathrm{MW}$. Since the total real capacity of DG is close to total real power demand of the system, the search procedure for best locations for placement of LPF DGs is stopped and buses 11, 17, 39 and 50 are identified as the best locations for placement of LPF DG.

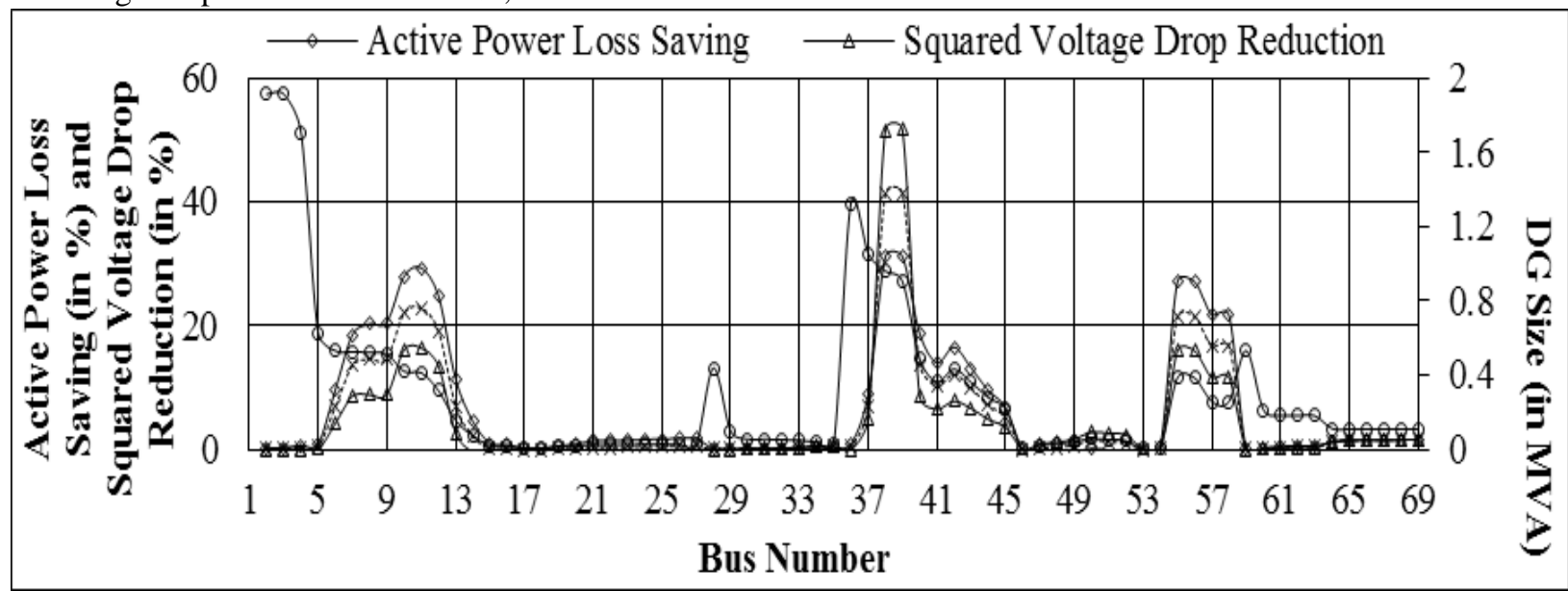

Fig. 11: Maximum real loss saving, voltage drop reduction and optimal size of LPF DG after placing 2.17 and 0.59 MVA, LPF DG at buses 50 and 17, respectively, in 69-bus network 


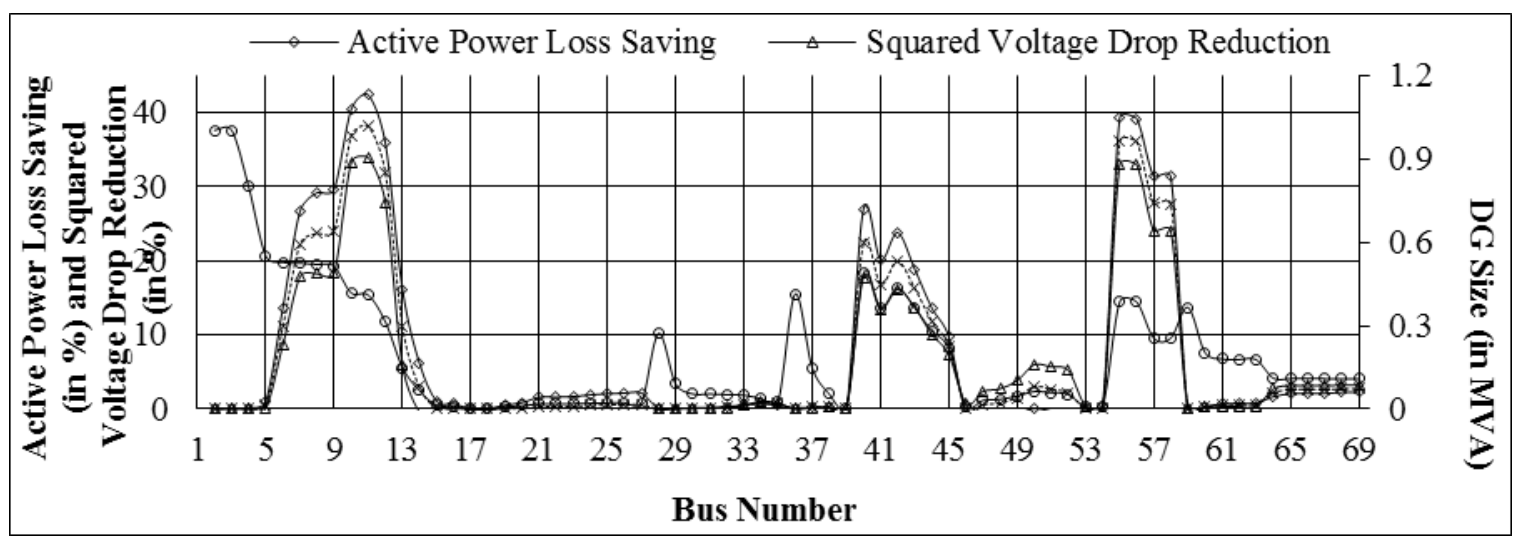

Fig. 12: Maximum real loss saving, voltage drop reduction and optimal size of LPF DG after placing $2.17,0.59$ and 0.91 MVA, LPF DGs at buses 50, 17 and 39, respectively, in 69-bus network

The results for identification of best buses for the placement of LPF DGs in 69-bus network are presented in Table 2. The real losses and total squared voltage drop in base case system are $225 \mathrm{~kW}$ and $0.179 \mathrm{kV}^{2}$. Using the proposed technique, a LPF DG of 2.17 MVA size is found suitable for the placement at bus 50 as seen from Fig. 10 and it results the real loss saving of $200.86 \mathrm{~kW}$ and squared voltage drop reduction of $0.16 \mathrm{kV}^{2}$. After placing 2.17 MVA LPF DG at bus 50, a new load flow solution is obtained which indicates that the system has real loss of $23.36 \mathrm{~kW}$ and squared voltage drop of $0.018 \mathrm{kV}^{2}$. To find out the site and size of second LPF DG, again the proposed method is applied to 69-bus network, with 2.17 MVA, LPF DG connected at bus 50 and it is found that 0.59 MVA, LPF DG at bus 17, as seen from Fig. 11, offers maximum benefits (real loss saving of $15.98 \mathrm{~kW}$ and squared voltage drop reduction of $0.011 \mathrm{kV}^{2}$ ) to the network. After placing 0.59 MVA LPF DG at bus 17, a new load flow solution is obtained which indicates that the system has real power loss of $7.36 \mathrm{~kW}$ and squared voltage drop of 0.007 $\mathrm{kV}^{2}$.

Table 2: Results for LPF DG placement in 69-bus electrical network with $w_{1}=0.5$ and $w_{2}=0.5$

\begin{tabular}{|c|c|c|c|c|c|c|c|}
\hline \multicolumn{3}{|l|}{ Initial System Condition } & \multicolumn{5}{|c|}{ Result with DG installation } \\
\hline System Description & $\begin{array}{l}\text { Real } \\
\text { Loss } \\
(\mathbf{k W})\end{array}$ & $\begin{array}{l}\text { Squared } \\
\text { Voltage } \\
\text { Drop } \\
\left(\mathbf{k V}^{2}\right)\end{array}$ & $\begin{array}{ll}\text { No } & \text { of } \\
\text { DG } & \\
\text { placed } & \end{array}$ & $\begin{array}{l}\text { Bus for DG } \\
\text { placement }\end{array}$ & $\begin{array}{l}\text { DG Size } \\
\text { (MVA) }\end{array}$ & $\begin{array}{l}\text { Real Loss } \\
\text { Saving } \\
(\mathbf{k W})\end{array}$ & $\mid \begin{array}{lr}\text { Squared Voltage } \\
\text { Drop reduction } \\
\left(\mathbf{k} \mathbf{V}^{2}\right)\end{array}$ \\
\hline Original base case system & 225.00 & 0.179 & 1 & 50 & 2.17 & 200.86 & 0.160 \\
\hline $\begin{array}{l}\text { Base case system with } 2.17 \\
\text { MVA, LPF DG connected to bus } \\
50\end{array}$ & 23.36 & 0.018 & 1 & 17 & 0.59 & 15.98 & 0.011 \\
\hline $\begin{array}{l}\text { Base case system with } 2.17 \text { and } \\
0.59 \text { MVA, LPF DG connected } \\
\text { to buses } 50 \text { and } 17 \text {, respectively }\end{array}$ & 7.31 & 0.007 & 1 & 39 & 0.91 & 2.28 & 0.004 \\
\hline $\begin{array}{l}\text { Base case system with } 2.17,0.59 \\
\text { and } 0.91 \text { MVA, LPF DG } \\
\text { connected to buses } 50,17 \text { and } \\
39 \text {, respectively }\end{array}$ & 5.03 & 0.003 & 1 & 11 & 0.41 & 2.13 & 0.001 \\
\hline Original base case system & 225.00 & 0.179 & 4 & $11,17,39,50$ & $\begin{array}{l}0.59,0.45 \\
0.91,2.05\end{array}$ & 222.76 & 0.178 \\
\hline $\begin{array}{l}\text { Base case system with } 0.59, \\
0.45,0.91 \text { and } 2.05 \text { MVA, LPF } \\
\text { DG connected to buses } 11,17, \\
39 \text { and } 50 \text {, respectively }\end{array}$ & 2.01 & 0.001 & - & - & - & - & - \\
\hline
\end{tabular}

The proposed method is further applied to 69-bus network with 2.17 and 0.59 MVA, LPF DG at buses 50 and 17, respectively, to compute the location and size of third LPF DG and it is found that 0.91 MVA, LPF DG at bus 39, as seen from Fig. 11, offers maximum benefits (real loss saving of $2.28 \mathrm{~kW}$ and squared voltage drop reduction of $0.004 \mathrm{kV}^{2}$ ) to the network. After placing 0.91 MVA, LPF DG at bus 39, a new load flow solution is obtained which indicates that the network has real loss of $5.03 \mathrm{~kW}$ and squared voltage drop of $0.003 \mathrm{kV}^{2}$. 
After this, the location and size of fourth LPF DG is computed by the proposed method and it is seen from Fig. 12 that 0.41 MVA, LPF DG at bus 11 offers maximum benefits (real loss saving of $2.13 \mathrm{~kW}$ and squared voltage drop reduction of $0.001 \mathrm{kV}^{2}$ ) to the network. Since after placing fourth DG in the network, the total real power capacity of becomes 3.5 MW which is close to the total real demand of the network, no more DG is attempted for siting and sizing and buses 11, 17, 39 and 50 are identified as the suitable sites for the placement of LPF DG in 69-bus distribution network.

After identifying buses $11,17,39$ and 50 as the suitable sites for the placement of LPF DG, the appropriate sizes of LPF DGs at these buses are computed simultaneously from eqs. (18) to (20). The optimal sizes of LPF DG at buses 11, 17, 39 and 50 are 0.59, 0.45, 0.91 and 2.05 MVA, respectively. By placing these DGs with their calculated sizes at respective buses, the real loss of $2.01 \mathrm{~kW}$ and total squared voltage drop of $0.001 \mathrm{kV}^{2}$ are obtained as shown in Table 2.

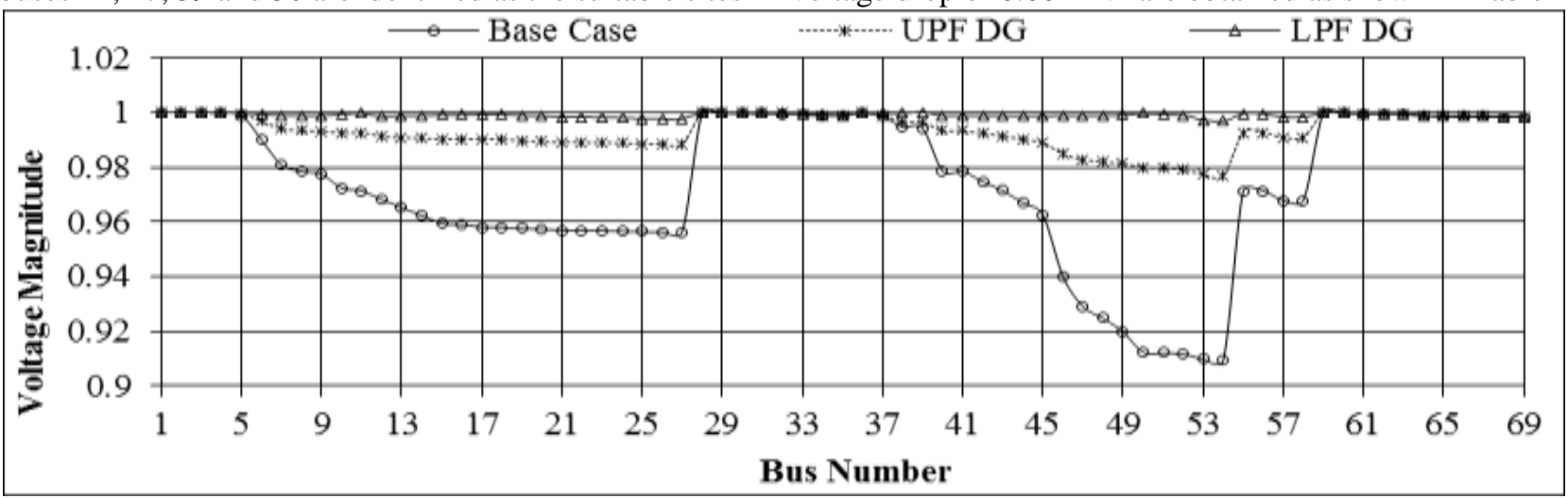

Fig. 13: Voltage profiles of 69-bus network for different cases under consideration

The voltage profiles of a 69-bus electrical network for the various considered cases are shown in Fig. 13. These voltage profiles are found after placing all the DGs, as given in the last row of Tables 4 and 5, for UPF and LPF operation, respectively, in the network. It is clear from Fig. 13 that the placement of DG units in 69-bus network using this technique considerably improves the network voltage profile. However, among different power factor of DG considered, the best voltage profile is seen, when DGs are operating at LPF. With LPF DGs in the network, the voltage magnitudes at all the buses are varying within the narrow range of 0.99 to $1.0 \mathrm{pu}$. However, with UPF DGs operation in the network, the voltage magnitudes lie in the range of 0.97 to $1.0 \mathrm{pu}$.

Summarizing different cases given in Tables 1 and 2 and Fig. 13, it is concluded that the DGs operation at LPF improves the performance of 69-bus network in a better way in comparison to that at UPF DG operation.

\section{CONCLUSIONS}

This paper presented a method for sizing and siting of DGs in the electrical distribution network. The developed methodology has been applied on a 69-bus network considering different values of DG operating power factors. Obtained results shows best real loss reduction and voltage profile improvement of the network under consideration. Among different power factors assumed, the DG operation at load power factor can enhances the system performance greatly, compared to that at unity power factor.

\section{REFERENCES}

1. Abu-Mouti F.S., and El-Hawary M.E., "Optimal distributed generation allocation and sizing in distribution systems using artificial bee colony algorithm”, IEEE 2090-2101, October 2011.

2. Acharya N., Mahat P., and Mithulananthan N., "An analytical approach for DG allocation in primary distribution network", International Journal of Electrical Transactions on Power Delivery, Vol. 26, No. 4, pp.

Power and Energy Systems, Vol. 28, No. 10, pp. 669-678, December 2006.

3. Aman M.M., Jasmon G.B., Bakar A.H.A., and Mokhlis H., "A new approach for optimum DG placement and sizing based on voltage stability maximization and minimization of power losses", Energy Conversion and Management, Vol.70, pp. 202-210, 2013.

4. Atwa Y.M,, EI-Saadany E.F,, Salama M.M.A., and Seethapathy R., "Optimal renewable resource mix for distribution system energy loss minimization", IEEE Transactions on Power Systems, Vol. 25, No. 1, pp. 360-370, February 2010.

5. Chiradeja P., and Ramkumar R., "An approach to quantify the technical benefits of distributed generation", IEEE Transactions on Energy Conversion, Vol. 19, No. 4, pp. 764-773, December 2004.

6. Elsaiah S., Benidris S., and Mitra J., "Analytical approach for placement and sizing of distributed generation on distribution systems", IET Generation, Transmission and Distribution, Vol. 8, No.6, pp. 1039-1049, June 2014.

7. Gozel T., and Hocaoglu M.H., "An analytical method for the sizing and siting of distributed generators in radial systems", Electric Power Systems Research, Vol. 79, pp. 912-918, 2009.

8. Hedayati H., Nabaviniaki S.A., and Akbarimazd A., "A method for placement of DG units in distribution network", IEEE Transactions on Power Delivery, Vol. 23, No. 3, pp. 1620-1628, July 2008.

9. Hung D.Q., Mithulananthan N., and Bansal R.C., "Analytical expressions for DG allocation in primary distribution networks", IEEE Transactions on Energy Conversion, Vol. 25, No. 3, pp. 814-820, September 2010.

10. Hung D.Q., Mithulanathan N., and Bansal R.C., "Analytical Strategies for renewable distributed generation integration considering energy loss minimization", Applied Energy, Vol. 105, pp. 75-85, 2013.

11. Khan H., and Choudhry M.A., "Implementation of distributed generation algorithm for performance enhancement of distribution feeder under extreme load 
growth", International Journal of Electrical Power and Energy Systems, Vol. 32, No. 9, pp. 985-997, November 2010.

12. Khatod D.K., Pant V., Sharma J.D., "Evolutionary programming based optimal placement of renewable distributed generators", IEEE Transactions on Power Systems, Vol. 28, No. 2, pp. 683-695, 2013.

13. Murthy V.V.S.N., and Kumar A., "Comparison of optimal DG allocation methods in radial distribution systems based on sensitivity approaches", International Journal of Electric Power and Energy Systems, Vol. 53, pp. 450-467, December 2013.

14. Ochoa L.F., and Harrison G.P., "Minimizing energy losses: Optimal accommodation and Smart operation of renewable DG", IEEE Transactions on Power Systems, Vol. 26, No. 1, pp. 198-205, February 2011.

15. Quezeda V.H.M., Jua-Rivier Abbad., and T. Gomez., "Assessment of energy distribution losses for increasing penetration of DG", IEEE Transactions on Power Systems, Vol. 21, No. 2, pp. 533-540, May 2006.

16. Wang C., and Nehir M.H., "Analytical approaches for optimal placement of distributed generation sources in power system", IEEE Transactions on Power Systems, Vol. 19, No. 4, pp. 2068-2076, 2004.

17. Celli G., Ghiani E., Mocci S., and Pilo F., "A multi-objective evolutionary algorithm for siting and sizing of distributed generation", IEEE Transactions on Power Systems, Vol. 20, No. 2, pp. 750-757, May 2005.

18. El-Khattam W., Bhattacharya K., Hagazy Y.G., and Salama M.M.A., "Optimal investment planning for distributed generation in a competitive electricity market”, IEEE Transactions on Power Systems, Vol. 19, No. 3, pp. 1674-1684, August 2004.

19. Mendez V.H., Rivier J., De la Fuente J.I., Gomez T., Arceluz J., Marin J., and Madurga A., "Impact of distributed generation on distribution investment deferral", International Journal of Electrical Power and Energy Systems, Vol. 28, No. 4, pp. 244-252, May 2006.

20. Hung D.Q., Mithulanathan N., and Bansal R.C., "Multiple distributed generators placement in primary distribution networks for loss reduction", IEEE Transactions on Industrial Electronics, Vol. 60, No. 4, April 2013, pp. 1700-1708.

21. Shukla T.N., Singh S.P., Srinivasarao V., and Naik K.B., "Optimal sizing of distributed generation placed on radial distribution systems", Electric Power Components and Systems, Vol. 38, No. 3, pp. 260-274, January 2010.

22. Kashem M.A., Le A.D.T., Negnevitsky M., and Ledwitch G., "Distributed Generation for minimization of power losses in distribution systems", IEEE Power Engineering Society General Meeting, Montreal, Que, pp. 1-8, 2006.

23. Elgerd O.I., "Electric energy systems theory: An introduction", McGraw-Hill, 1971.

24. Gopiya Naik S., Khatod D.K., and Sharma M.P., "Sizing and siting of DG in distribution networks for real power loss minimization using analytical approach", IEEE Conference on Power Energy and Control (ICPEC 2013), Dindigul (TN), pp. 740-745, February 6-8, 2013.

25. Gopiya Naik S., Khatod D.K., and Sharma M.P., "Analytical approach for optimal siting and sizing of distributed generation in radial distribution networks", IET Generation, Transmission and Distribution, Vol. 9, No. 3, pp. 209-220, February 2015.

26. Chiang H.D., and J.-Jumeau R., "Optimal network reconfigurations in distribution systems: Part 2: Solution algorithms and numerical results", IEEE Transactions on Power Delivery, Vol. 5, No. 3, pp. 1568-1574, July 1990. 